\title{
Dreams and Actualities: Danforth Fellows in Mid-Career
}

\section{R. Eugene Rice}

In 1951, the bulletin boards of colleges and universities across the country began carrying the announcement of the Danforth Graduate Fellowship, stating that appointment as a Danforth Fellows was one of the major academic honors available to persons interested in preparation for college teaching. In the fall of 1979, the St. Louis-based foundation announced that the 1980 class of Danforth Fellowship recipients would be the last. Since the appearance of that initial announcement, over 3,500 Fellows have been elected, through highly competitive selection process, to one of the several graduate fellowship programs sponsored by the Danforth Foundation. More than $\mathbf{8 0}$ percent of the recipients of these academic awards have gone on to complete their degrees and are now serving on the faculties of, or providing administrative leadership for a broad range of colleges and universities across the nation-from Stanford to Onondaga Community College, from Harvard to New Mexico State. This is a study of the personal and professional development, of what actually happens to the dreams and aspirations, of these talented men and women whose careers from the start promised so much.

\section{Three Distinct Groups of Fellows}

The fellowship recipients represented in this study were drawn from three discrete groups. The first groups was made up of Danforth Fellows appointees in the 1950's, begiming with the first class of 1952 
through the class of 1960. By now these professors are, for the most part, established, tenured faculty. All have been teaching for at least ten years and most are now confronting the perplexing problems that commonly emerge in mid-career.

The second group received their Fellowship appointments in the mid-1960's, Danforth and Kent Fellows appointed between 1964 and 1967. At the time of the study these Fellows had been teaching for approximately five years, were not yet tenured in most cases, and were living with the increasing strains that are normally attendant to that situation - strains that continue to be seriously exacerbated by the pressures of economic and institutional retrenchment.

The third group was composed of recipients of the Graduate Fellowships for Women, appointed between 1965 and 1970. Although most of these women received their Fellowships at approximately the same time as the younger Danforths and the Kents, and are closer in age to the older Danforth group, their personal and professional situations are quite distinct, and their perceptions of their lives as teachers are markedly so.

The opportunity to do the study arose when the Foundation, concerned about the future of the academic profession and the needs of college and university faculty in mid-career, decided to renew its relationship with Fellows who had completed their degrees and were well along in the pursuit of their careers. More than 300 Fellowship recipients were invited to two Faculty Workshops on the Profession of Teaching, the first in the spring of 1975 and another in the spring of 1976.

In preparation for the two Workshops, all the invited participants were sent the statements of personal and professional aspirations that they themselves had written when applying for their Fellowships, ten, fifteen, and, in some cases, twenty-four years earlier. Each Fellow was asked to submit a written response to that statement, reflecting on his or her own development during the intervening years. The participants were asked specifically to comment on the relationships between their stated aspirations and what actually happened in their lives, and say something about their successes and failures, to reflect on the integration of the personal and professional aspects of their lives, and to speak about how the institutions of which they have become a part have 
influenced their personal and professional development. They were also invited to speculate briefly about their futures.

Eighty-five percent of the Fellows attending the Workshops responded to their application statements making for a total of 224 responses. Some of the responses were hurried and cursory-taking care of another bureaucratic demand. But for most of the Fellows the relationships with the Foundation has meant more than substantial financial support; it has been a genuine "relationship of encouragement" as was originally intended, and the responses were frequently long, thoughtful, remarkably open, and some beautifully written. This paper is an attempt to bring together the common themes and concerns, the developmental issues as well as the complex social/institutional/ historical questions that emerge from these very private, personal statements of men and women chosen on the strength of uncommon promise - their potential for contributing to the profession of teaching.

\section{Teaching: Dreams and Development}

This study, like the recent concern for faculty development in higher education generally, is a part of a much larger societal interest in adult development. What youth, the "identity crisis," and Erik Erikson were in the sixties, "the mid-life transition," generativity, and Daniel Levinson have become currently. Levinson influenced the conceptualization of the first Workshop, attended himself, and the report of his research, "The Psychosocial Development of Men in Early Adulthood and the Mid-Life Transition," was sent to the participants with the request for their own developmental assessment. ${ }^{1}$

An important theme running through Levinson's research on the life history of adults is the significance of the dream or vision of one's own future as a "vitalizing force for adult development." 2 In their own original statements, when applying for the Fellowships, the Fellows were compelled to articulate their dreams, their visions of their futures. The responses called for an assessment of those dreams. As might be expected, there were a rich variety in the many sensitive, sometimes painful statements. Some of what was recounted was highly idiosyncratic, but much was held in common, shared particularly within the three distinct groups of Fellowship recipients. Common social condi- 
tions - economic, political, and symbolic - had a profound impact on the interrelationships of dreams, development, and actualities.

The 1950's Fellows. The Fellows appointed in the 1950's found that there was extraordinary continuity between their career aspirations and what had actually happened to them professionally; while at the same time, they were most struck by the disturbing disparity in their understanding of their world, themselves, and what it finally meant to teach, day-to-day, in a college or university.

A number in the older group of Fellows began their statements with comments similar to the following: "The most immediately surprising thing is the closeness of the stated aspirations and what actually happened in my life." They were speaking primarily of the expected profession in their professional career patterns-completion of advanced degrees, first teaching appointment in accord with expectations, tenure in due course, and the appropriate promotions. Without detracting from the significant accomplishments of this group of Fellows, it should be noted that they were entering the teaching profession at a very propitious time-new programs were being developed, funds were available for expansion, higher education was in its heyday. Aspirations to teach in "a small, Christian-oriented, liberal arts college" were turned aside "with a modest sense of guilt and regret." As one 1957 Fellow who is now on the faculty of leading research university on the West Coast put it: "I wanted to see if I could do it at the big U-and it was clearly a choice to go for the 'status trip'." These were hard choices-but choices, nonetheless, options that in retrospect seem almost unique to the time. Most of the 1950's Fellows are very much satisfied with their decisions. A 1955 Fellow, acknowledging how really fortunate this cohort of professors was and is, states candidly: "Status in academic positions in recent years is far more a matter of where one was able to situate himself in the mid-60's than any matter of ability.

The congruity that the older Fellows found between earlier aspirations and their basic career pattern was not as immediately evident when they turned to issues that were more symbolic - issues having to do with meaning. The larger religious questions, questions of value, and the context of meaning have always been important in the Danforth Fellowship program. In addition to academic ability and a clear 
commitment to teaching, Fellowship candidates were expected to demonstrate a concern for the significance of ethical or religious values. In reviewing their original statements of aspiration, almost all of the 1950's Fellows spoke of being "amused and embarrassed," "somewhat shocked," and not recognizing the "me" who wrote the earlier statement.

References to sources of transcendent meaning and work, one's "vocation," were inextricably intertwined in most of the initial statements. There was no doubt that the profession of teaching would be fraught with significant meaning. As a senior at Notre Dame (not all the older Fellows were descendents of Max Weber's "ascetic Protestants"), one Fellow wrote: "If vocation of the Christian teacher is anything, it is to help form in young people a humble knowledge, a loving understanding, a reverent love of the mystery of human reality, of being of God." That was a lot to expect of one's work-even teaching -as most were soon to find out.

For a number of the older Fellows the religious language that meant and expresses so much in the fifties still resonates. A Fellow in the original class writes: "In my middle years, I consider myself more than ever committed to the Christian faith." Many, however, are struggling to find a new metaphor, a new rhetoric to express that which gives meaning and significance to life. One writes:

My metaphor...now would be an artistic rather than a religious one. I would talk, with Mrs. Ramsey of Virginia Woolf's To the Lighthouse, of seeking form to hold off the flux of the fluidity 'out there'. That would be my 'ordeal' rather that 'the demands toward perfection which God makes upon both our souls and our intellects!"

It will be disconcerting to some to find that the winners of the national fellowship competition-presumably among the best of the graduating seniors in those years - reflected so directly the temper of the times. Eisenhower was in the White House eulogizing "deeply held faith" as the bulwark of the nation, and the religious "revival" of the postwar years, in stride with the baby boom, hit its peak in 1957. In reviewing their earlier statements, the 1950's Fellows found them to be "naive," even "imnocent" and "bland." They were bothered by the 
"tidiness" and the "certainty." A 1959 Fellow, now a professor in the University of California system, compared his old and new selves:

I missed a sense of playfulness, a dash of irony, some bite of wit, a bow to complexity and ambiguity...The 1958 self seemed vulnerable to unexpected challenges to his beliefs and expectations; the 1975 self, for better or worse, thinks of himself as more tough-minded, more skeptical of easy answers to complex questions, more willing to admit his own creature has within the forced matrix of history and culture. The 1958 self, with a broad and rather unreflecting brush, painted big, sweeping words like "Ideas" and "People." The 1975 self is more at home with quotation marks, to indicate "perspective."

The transforming impact that effective teaching was to have on students and society-at-large has not been as fully evident in the experience of the 1950's Fellows as they had hoped earlier. "After ten years of teaching," one wrote, "I' $m$ afraid I find my career as a teacher far less satisfying to me, and far less significant to the lives of my students, than (is indicated) in these enthusiastic words." Another comments: "I am soberly (somberly) a ware of limitations for changing another person 'for good'."

It is not teaching in the classroom, however, that is the major source of discouragement for these Fellows. In fact, most would rather agree that: "...the teaching function is the one that is personally sustaining, and the one that continues to mean the most." What is most disheartening for these Fellows is all the other "stuff" that is a part of the profession of teaching: the vacuous relationships with colleagues, the competitive ethos pervading departments, meaningless committee work, and an inappropriate and/or unjust reward system.

The depth of discouragement found among some of the 1950's Fellows now in mid-career is expressed in this statement: "I feel I was almost completely unprepared for professional disappointments, pettiness, intellectual laziness (in others and myself), and sheer exhaustion." Another queries: "But when does 'settling for less' become not a mark of maturity but of fatigue? I fear the latter, and sense a deep need for a source of refreshment and renewed vigor. I do not see where it will spring from." That same Fellow, more "professionally successful" than most, gave expression to a feeling that comes to him in his worst moments: "That terrible sense of hollowness: hollow col- 
leagues, hollow students, hollow self, engaged in a ritual with its core meaning sucked out."

As both Calvin and Freud know, the significance of work is derived from a larger context of meaning. In discussing the importance of work, Freud points out that "in his work (the individual) is at least securely attached to a part of reality, the human community." Robert Jay Lifton, in his most recent book, carries the argument further.

What we call work is a uniquely important boundary between self-process and social vision. Perhaps for the first time in history very large numbers of men and women are beginning to demand harmony and meaning at that boyndary; to demand a reasonable equation between work and "works."

Since the 1950's, American society-its colleges and universities particularly - have passed through a period of severe historical dislocation. The older academic community and the symbolic context that provided meaning for the profession have been radically altered. Many of the Danforth Fellows who began their careers in the fifties, in that other world, are now having to face up to the symbolic consequences of that historical dislocation. They are openly engaged in a process of resymbolization, that they hope will provide the kind of meaning for their work-their profession - that Lifton suggests is now being demanded.

Fellows Appointed in the Mid-1960's The undergraduate careers of most of the Fellows in this group coincided roughly with the Kennedy years, a time filled with the hopeful thetoric of the New Frontier, the Peace Corps, an envisioned Camelot. Several had themselves been Freedom Riders in the South, and in August of 1963 had been present at the March on Washington to hear Martin Luther King's "I Have A Dream." They had sung "We Shall Overcome" often and with confidence.

The youthful idealism that characterized the application statements of the 1950's Fellows is abundantly evident in the statements of this group. The religious concerns are there, but the expressions of confidence are less personalistic and have more to do with social and institutional life-justice and change. There was the conviction that talented people with perseverance and new, imaginative strategies 
could substantially influence established institutions. And there was the confidence that higher education-the teaching profession, particularly - was to play a key role in effecting institutional and societal change.

The events of the past ten years and the individual experiences of these Fellows have eroded that earlier confidence. And the erosion is serious, qualitatively different from the "de-illusioning process" that Levinson and others find normally occurring in the development of young adults. ${ }^{5}$ The extent of the disillusionment and some reasons for it are immediately evident in the responses of this Kent Fellow:

Then, I "knew" that people could be made better and the world could be saved through education. Now, rather, I hope for that, but with a hope that seems increasingly qualified and limited. And as the ideal fades, the sense of mission that accompanied it is increasingly dissipated, and I struggle against a growing indifference (forced adaptation? realism) and cynical entrenchment.

For another, the disillusionment has turned to bitterness:

It's hard to keep the bitterness out. At this moment in time, we're all victims; we all have something to be bitter about. Yes, I mean the absence of the "Liberal Dream" (whatever that was) of the Sixties (could it have been, simply, the vision of a workable multi-ethnic democracy, a sense of shared purpose in individual lives?) Yes, I mean the prevailing winds of the economy, against which all defenses of ego and ideals are like a paper bag in a hurricane. Yes, I mean all the betrayals, petty and great, willed and unwilled, which leave us the victims of a spiritual landscape from which alien anthropologists might extract samples drier than any moonrock. Handfuls of dust.

A number in this group of younger Fellows had difficulty with what one aptly calls the "herculean fallacy."It took a variety of forms, but for this 1966 appointee it referred to: "My deluded impression that my own passionate interests would somehow remake my social and professional environment, with its rigid demands." Along with many beginning their teaching careers in the early '70's, he found that:

The available world is just too tough for that, its patterns too well entrenched. Confronted with this dismaying discovery, I have taken comfort in the fact that most of my admired and respected friends have 
discovered the same - or very similar-things. I have also had to give considerable thought to strategies of professional survival. A great deal of my energy has been absorbed with the questions of how to make a career I can myself respect....

In their original statements, the Fellows applying in the mid-60's, often used religious language to express their basic values and commitments. However, the use of religious language, in contrast to the applicant statements of the 1950's Fellows, is much more restrained. In their 1975 and 1976 statements, what is most striking, given their comments, is the extent to which the faith itself has been abandoned. One '64 Danforth wrote: “...I was frankly embarrassed by the outright and unqualified profession of belief in Christian doctrine, a belief abandoned within a year or two after the statement was written." Another said: "religion which once was important to me is now a forgotten part of myself."

Particularly intriguing was the extent to which those trained in religious studies were reluctant to use the language. This statement is typical: "Increasingly, I have moved away from expressing my own beliefs and values in theological, or perhaps even in religious terms." Another, taking a stronger position, but one that is significant given the Foundation's concern for religious values, wrote: "I think it is fair to say that now the Christian tradition is of interest to me only as an historical phenomenon. I would never be tempted to articulate my deepest concerns today in Christian or theistic terms." In reference to his teaching he goes on to say: "I am reluctant to reveal the depths of my own indifference...Fortunately, I rarely have to state my own convictions explicitly."

The immediate overriding concern of the 1964-1967 Danforths and Kents-some not yet tenured-is the impact of the institutional retrenchment on their lives. In a summary of one of the Workshops, Elden Jacobson, a 1975 Danforth Fellow, captures the mood of the younger group in an account of their reaction to a comment made by Daniel Levinson in his address to the gathering.

In his soft, often hesitant, manner, Levinson casually noted in his own autobiographical statement the fact that he had moved, in 1964 or 1965 , from Harvard to a tenured position at Yale; too, he observed, a genuine 
sense of the human tragedy did not seen possible to him until one had lived through (and survived) the crisis of mid-life; that is to say, the early forties. "That is simply absurd," said one young academic who, in his mid-thirties, has just been denied tenure at a mediocre state college. "Harvard to Yale, for Christ's sake!" decried another. With varying degrees of intensity, younger faculty insisted on describing their situations with the language of hopelessness, with an impotance to respond save in frustration and anger. They are-or perceive themselves about to become - unwilling elements in a floating card game where one grabs whatever is dealt. This issue is survival.

For many of the younger faculty, whose "dreams" were nurtured into being in more optimistic and prosperous days, the full realization of those aspirations is blocked by a situation marked by restraint and limitation. This is true even for some of those having more secure positions, they feel boxed in-trapped. In the words of one Kent Fellow:

Above all I want to avoid the acceptance of my present as permanent. In short, I am struggling against "settling down." Yet at times I feel I am dying a slow professional death in my present position. But given the present situation in academia (depressed) there may not be a ladder to climb.

According to Daniel Levinson's developmental scheme, a period of "settling down" in the early thirties is followed by a burst of growth and change that begins in the middle thirties. Levinson calls it the BOOM period, Becoming One's Own Man. When the statements of these younger professors are viewed in the light of Levinson's developmental theory, one wonders what will happen to this group of young faculty who will enter the BOOM period with no place to go, yet not being able to "settle down" where they are, pulled on by a dream cultivated in a more buoyant time. As one Fellow, appointed in 1967, put it: "Staying put is hard for those accustomed to moving on."

\section{Graduate Fellowships for Women, 1965-1970}

The recipients of the GFW awards who have been included in this study received their Fellowships between 1965 and 1970. Almost all are now directly engaged in college or university teaching, although 
a number are struggling with problems that continue to plague faculty members with part-time appointments. These women are confronted with the same depressed job market as the younger Danforth and Kents, but their perceptions of their situations are quite differentmuch less pessimistic on the whole, despite the added burden of not only sex discrimination (affirmative hiring has had little real effect), but because they are older and are being discriminated against on the basis of age.

Although one woman echoed the Danforths and Kents in saying: "I wish that I had gone into my profession with my eyes open just a little more widely," the GFW's seem much better prepared to adapt to the changing situation in higher education. It could be argued that they are better able to cope with adverse change because they have all had substantial experience outside of academia; and, as a consequence, are capable of viewing the academic profession and the university as an institution in a comparative way. For most Danforths and Kents this is not the case. They have moved, until most recently, from one success to another, all within the confines of the academy, and are having to face professional reversals for the first time, ill prepared. The GFW's in contrast, have been, as the sociologists would say, socialized for contingency. They have had to constantly adapt to a disorderly career pattern. Their own plans have had to be altered regularly to accommodate the demands of marriage and the family.

The GFW's are facing retrenchment in their profession with greater equanimity, partly because their aspirations were tempered by the time-no mention of Nobel Prizes in their original statements, but also because their experiences have prepared them to be more flexible and adaptive. An admittedly extreme example is found in these excerpts from the response of a GFW who, contrary to what might be expected, does not have the support of a spouse:

I found my niche, my special work my delight at (a private urban university). What can count more than that...I plan to move laterally to my next job; i.e., same rank, more interesting job. I look at jobs in terms of the excitement (or people, of ideas) I will get from them...For an exciting enough school I would be not unhappy with going 'down' the ladder to an instructorship. If nothing shows up (and something always does), I can stay where I am, redefining my job to increase my 
satisfaction and build outside activities for this same purpose. Thinking about learning math; perhaps an MBA.

This more optimistic, adaptive spirit identified with the GFW's is clearly evident when the GFW's are compared with the other two faculty groups in this study. But, when the 1965-1967 GFW's are compared with the more recent $1968-70 \mathrm{GFW}$ appointees, a significant qualification must be made. The more recent GFW appointees are less hopeful, the strains are evident in their responses to their application statements. One writes: "The exuberance conveyed in the buoyant tone has changed and darkened. I see those beliefs now as haloed islands in a rough and turbulent academic sea of fiscal fear and lop-sided priorities." The policies of "last in, first out," and "full-time work for part-time pay," to which many of these women are being subjected, just at a time when they are being encouraged to expect more, have begun to take their toll.

In comparing the responses of the three groups of faculty members, one is immediately struck by how much more seriously the women take their familiar roles-parent and spouse- than do the men. In making this generalization, it should be pointed out that we are talking specifically about GFW's appointed between 1965-1970. During the decade of the 1970's more than half of the Danforth and Kent Fellowships went to women. There is reason to believe that these women will relate the personal and professional aspects of their lives in ways that are substantially different. ${ }^{6}$

A 1966 GFW who is not a department chairperson in an important Eastern university, speaks for many of the women appointed in the early years of the program when she writes:

I approach both my studies and my profession with eagerness and dedication but never with the intention of allowing them to supersede family priorities. I felt then, as I do now, that success and achievement are exhilarating and deeply satisfying and that I would like them, if possible, to be part of my life. However, they would be totally empty and meaningless unless I had a loved one by my side to share the trials and the pride, and a loving home and family atmosphere within which to replenish my soul. 
These commitments have created serious professional problems as might be expected. Good positions have been lost where family responsibilities have been given precedence, and some guilt generated when compromise was required. A $1967 \mathrm{GFW}$ writes enthusiastically about the challenge of teaching older students and the changes she was able to effect in her department, but then adds:

The institution of which I was a part...contains enough diversity within it to be a great home for me. There is no doubt that I would have been the next department chairman in our college, had I not had to leave, BUT, unfortunately, my husband's job change necessitated our move...and now...I will have to start all over to carve out a situation where I can work and be appreciated for what I am. I don't feel hopeless about this, but...

Even for those who have worked out a "well-balanced and satisfying" relationship between the personal and professional aspects of their lives, there is always the threat that a change will be required that will not be of their choosing. One writes: "I would like to be more in control of my own situation, and have to push myself to take life as it comes, rather than as I would choose it to be."

During the 1960's the roles of wife and mother were so thoroughly denied in the culture that professional roles for women were made distinctly secondary. Danforth fellowship policy directly reflected the sexism of the times and women were officially excluded from the Program from 1956 to 1964. Now it is the professional roles that are being given priority among the women Fellowship recipients. Ambivalence was evident in the 1950's as it is currently, but the emphasis in both periods is clear. The integration of love and work is hard to come by.

The GFW's appointed in the early years of the program have been caught in the transition from one emphasis to another and are trying gallantly to combine the best of both worlds Several write of schedules of 16 to 18 hours a day trying to meet the demands of their multiple roles. A 1967 GFW spoke of going through "periods of almost complete professional and personal schizophrenia..." A striking illustration is drawn from her graduate and school experience . "For years I took the bus from home to library and back, though I could have used 
the car, in order to give myself time to shift gears from personal and professional and back again while someone else shifted the actual gears." Having taken a teaching appointment located eighty miles away from her home the old schism is exacerbated even further. She concludes: "My husband is openly unhappy about the arrangement...I honestly don't know how long our family can survive this."

The GFW's struggle to overcome not only the bifurcation of the personal and the professional aspects of their lives, but are also wrestling with the separation of intellectual theory and analysis, on the one hand, and lived experience, on the other hand.

The sense of solidarity and the changes in consciousness engendered by the women's movement has been of critical importance here. Older patterns of authority, both intellectual and institutional have been profoundly relativized and are being challenged. As $1970 \mathrm{GFW}$ puts it: "To consciously identify with the interests of women in a patriarchal world is to take a political position, a pleasure I no longer deny myself." The definition of the profession itself is being subjected to a serious critique.

The GFW's included in this study are an impressive group of professional women who have committed themselves to an almost impossible constellation of roles. There is a realistic quality faced squarely, and there is a resilience in the pursuit of those aspirations that should make them especially effective in dealing with the new challlenges and restraints in the difficult days ahead.

\section{Becoming Professional}

The incongruity between the ideal conception of the profession of teaching that enticed the Fellows in formal preparation for the profession was most difficult to assimilate. The majority of the Danforths and Kents had spent their undergraduate years in small, private, liberal arts colleges-often church related. For graduate school contrast between the two extended well beyond size and sophistication.

During the late 1950's and the 1960's, when the faculty members under consideration here were engaged in graduate study, graduate departments were proliferating rapidly and becoming more narrowly specialized. This combination of rapid growth and differentiation had 
a profound effect on the profession and the students preparing to enter it. At the same time, Danforth Fellowship recipients were being selected on the basis of their broader talents and interests, a more holistic, integrated approach to the profession and their lives in society. The experience of many expressed in the statement of the English professor: "My graduate work in English at Columbia seemed increasingly distant from any life goal I had."

For many Fellows engaged in graduate work in the mid-1960's becoming professional was something to be resisted. A 1965 Danforth Fellow writes: "Graduate School was a long period of resistance to the professionalism, impersonality, and poor teaching I encountered." Another in that same class confesses that to become professional meant that: "my interest became more limited, parochial, more scholarly than intellectual." After seven years of university teaching this same Fellow still felt "an unhealthy conflict between so-called professional considerations, as inculcated in graduate study, and more humane and value-oriented possibilities, for which I chose this career in the first place."

The Fellows' references to their graduate school experiences underscore the importance of the role of the teacher as mentor. Where there was a professor who was willing and able to serve as a mentor, and where the relationship was constructive, the overall assessment of the years of graduate study is much more positive. Daniel Levinson defines the mentor as one who 'fosters the young person's development, not only by instructing him but also by believing in him, by sharing the Dream, by helping to create a space within which a newly emerging self can take shape and be given a place in the world."

A 1959 Danforth Fellow describes the helpful role that a graduate school mentor played in resolving an important professional issue with which he was wrestling:

A master teacher, with his skills sharpened to a fine edge by a decade spent in a liberal arts context, he nevertheless had research credentials sufficient to permit mid-career movement to a major graduate institution. As a mentor/role model he could therefore reinforce my own commitment to and interest in teaching while at the same time demanding a high level of competence in research skills. Over the years my internal resolution of the teaching/research issue has been to see them 
as aspects of the same intellectual process and I have come to think that for me personally the best teaching is done when both student and teacher are actively and collaboratively involved in the research process.

It is unfortunate that mentors of this sort were in evidence so seldom in the graduate school experience of these promising teachers. The judicious guidance of an experienced, thoughtful mentor is one of the best ways to provide a sense of vocation that has challenge and meaning and yet is also balanced and appropriate for the time.

\section{Colleagues}

Viewed from the outside, the life of the professor seems particularly rich in opportunities for sophisticated intellectual exchange and enlivening participation in a community of scholars. In their original application, many of the Fellows wrote effusively about the value of being a part of such a community. Their most recent statements indicate that this particular part of their professional "dream" had been a source of severe disappointment. Many complained of the "paucity of professional dialog", and a 1965 Danforth laments: "I an increasingly aware of the deadening effect of the faculty, a group at least as political as intellectual, indeed, a group that is even anti-intellectual precisely because it holds so tightly to its own narrow intellectability."

In a few of the smaller church-related colleges a sense of community and collegial support continues to flourish, but they are the exception. This statement from a professor in one of the leading private universities in the Midwest is more representive: "The paranoia and rivalry that I first encountered among my peers in graduate school days seem to be firmly entrenched dispositions in all levels of the academic profession."

Retrenchment, with the attendant competition for shrinking resources, had increased the isolation of colleagues from one another. The strain between junior and senior faculty - particularly in the more prestigious schools - seems to be getting especially bad. Junior faculty are often viewed as transients - just passing through. If collegial decision-making patterns ever did exist in departments and schools they are rapidly disappearing. A Fellow who had just survived a 
severely contested tenure decision in a leading professional school rendered his own judgement on the process of decision-making in one of our best universities: "Critical decisions are made by a self-delegated elite who seize power and impose their decisions upon others by methods I consider unethical."

The quality of teaching and its improvement depends in large measure on what has been referred to as "pedagogical colleagueship," the sharing of ideas and resources, direct observation, and the discussion of one another's teaching. If relationships among faculty are no better than is indicated in these Fellows' statements, the trust, respect, and critical support required for the maintenance of quality teaching is obviously lacking. Something must be done to counter the debilitating effects of the competition for advancement and the struggle to merely survive in a shrinking market.

\section{Love and Work}

The coordination of multiple roles-relating the personal and professional, particularly - has become increasingly difficult and emerges from this study as an issue of critical importance in the lives of faculty. This immediately evident not only in the statement of the women included in this inquiry, but permeates the responses of the men as well. In his 1959 statement a Danforth Fellow wrote with pride: "My wife-to-be is in complete accord with my plans and dreams." His more recent response points out that "There is no mention of her plans and dreams, largely because we both automatically expected her to live vicariously through my career." Those days are long past, finis. It is clear from the Fellows' statements that that sort of life structure is no longer an option, but finding a viable alternative is the source of considerable personal anguish. A 1960 Danforth writes: "The great change in our family pattern has ultimately been liberating, but the process has involved highly complex changes of roles with all the attendant confusion, uncertainties, and competition among family members of the family." Shortly after this statement was written, divorce proceedings were initiated. Opportunities for intelligent reflection on the consequences of these fundamental changes for the 
structure of our lives are all too rare, and can no longer be dismissed as professionally irrelevant.

\section{A Sense of Institutional Drift}

An overriding concern highlighted by this inquiry has to do with the fundamental purposes of the university and the raison d'etre of the profession itself. As an English professor from a large state university in the Midwest put it "I can't find the social ground and purpose of the activity my students and I mutually engage in. The same professor goes on the summarize the profound concern that many faculty have about the profession:

My profession seems to me to flounder, to have lost faith in its old models (and in the exemplary critics who personally embodied those models) and to be unable to find new ones...The result of floundering is a loss of cohesiveness and therefore a constant strain on intellect and emotion. Having lost the common ground that should nourish us, each individual has to invent his profession for himself.

The dreams, the professional aspirations articulated by these men and women at the beginning of their academic careers, confidently addressed questions about the purposes of the university and the contributions that one could make through the profession of teaching. In retrospect those original statements are seen as innocent, if not ill-informed, and, at points, incredibly naive; but there is a sense of bearing, of direction.

The intervening years have brought severe dislocation, some fragmentation, and an inchoate awareness of institutional drift, of aimlessness in both the university and the profession. Lifton has written persuasively about the deep uneasiness resulting from the contemporary breakdown in the shared sense of coherent meaning that is wide-spread in most of the professions. Following the lead of Thomas S. Kuhn, he finds the psychological professions boardering on a momentous shift in paradigm. ${ }^{9}$ The personal statements that inform this study suggest that the academic profession(s) - can the singular be used? - are in a similar place, having to confront the same sense of "psychohistorical dislocation." 
What is needed now is a reconstructed dream, a reconceptualization of the place of higher education in the society, that benefits from the historical chastening of those intervening years, but that goes on to provide the ideational base for a new integration, a coherent sense of direction, for both the university and the profession. Dreams can serve not only as a vitalizing force in the personal and professional development of individuals, but can contribute to the revitalization of institutions as well.

\section{References}

${ }^{1}$ See Life History Research in Psychopathology, Vol III, edited by D. F. Ricks, A. Thomas and M. Roff, University of Minnesota Press, 1974, pp. 243- 258.

${ }^{2}$ Ibid, p. 248.

${ }^{3}$ Civilization and Its Discontents, Doubleday and Company, Inc., Gade-City, 1958, p.21.

${ }^{4}$ The Life of the Self: Toward a New Psychology, Simon and Schuster, New York, p.142.

${ }^{5}$ Levinson, p. 250.

${ }^{6}$ Susan Uchitelle, "Review of the Graduate Fellowships for Women" St. Louis: The Danforth Foundation, 1975.

${ }^{7}$ Cities in the "Review of the Danforth Graduate and Kent Fellowship Programs," December, 1970, p.8.

${ }^{8}$ "The Psychological Development of the Student in the Psychology Graduate Department," Paper presented at the American Psychological Association, August, 1973, p. 11. Also, see Seasons of a Man's Life,Alfred A. Knopf, New York, 1978, pp.97-101.

${ }^{9}$ The Life of the Self, pp.151-171. 